\title{
O Intelectual Orgânico como Educador Popular: aproximações entre as ideias de Antonio Gramsci e Paulo Freire
}

\author{
The Organic Intellectual as a Popular Educator: approximations between Antonio \\ Gramsci and Paulo Freire ideas
}

Flávia Ribeiro Amaro ${ }^{1}$

\begin{abstract}
Resumo
O presente artigo visa levantar e discutir aproximações entre as ideias de Antônio Gramsci sobre o papel do "intelectual orgânico" e de Paulo Freire sobre o papel do "educador popular". Para tanto, foi realizada uma análise nas obras de ambos os autores, buscando por pontos de convergência em suas formulações teóricas sobre a relação estabelecida entre educação, cultura e política na dinâmica de vida das sociedades. Para ilustrar a questão, comenta-se sobre a atuação de intelectuais brasileiros engajados nos movimentos sociais de esquerda cristã ecumênica, pautados pelos pressupostos da Teologia da Libertação e comprometidos com a implementação do método de alfabetização de adultos “Palavra-Geradora” junto às Comunidades Eclesiais de Base.
\end{abstract}

Palavras-chave: Intelectual orgânico. Antonio Gramsci. Educador popular. Paulo Freire. Teologia da Libertação.

\begin{abstract}
This article aims to raise and discuss approximations between the ideas of Antonio Gramsci about the role of the "organic intellectual" and Paulo Freire on the role of the "popular educator". To this end, a bibliographic dimensioning was conducted in the work of both authors, seeking points of convergence in their theoretical formulations on the relationship established between education, culture, and politics in the dynamics of life of societies. To illustrate the issue, it comments on the performance of Brazilian intellectuals engaged in the social movements of the ecumenical Christian left, guided by the assumptions of Liberation Theology, and committed to the implementation of the adult literacy method "Word-Generator" with the Basic Ecclesial Communities.
\end{abstract}

Keywords: Organic intellectual. Antonio Gramsci. Popular educator. Paulo Freire. Liberation Theology.

\section{Introdução}

Em 2021, celebramos os cem anos de nascimento do patrono da educação

\footnotetext{
Doutora em Ciência da Religião pela Universidade Federal de Juiz de Fora. E-mail: flavia.ramaro@gmail.com.
} 


\title{
-Revista de Iniciação à Docência, v.6 , n. 2, 2021- \\ Publicação: dezembro, 2021 - ISSN 2525-4332
}

brasileira², Paulo Freire (1921-1997). Em razão dessa data comemorativa, pesquisadores das mais diversas áreas do conhecimento científico sentem-se instigados a revisitar o legado freiriano e retomar a discussão sobre os principais pressupostos teóricos de suas obras. Sobretudo, em se tratando desses tempos em que experimentamos a sensação de estarmos retrocedendo aos mesmos moldes conservadores e obscurantistas que estiveram em voga durante as décadas de 1960 e 1970.

Sentimo-nos convocados a rever as estratégias encontradas pelo educador e seus pares para o enfrentamento das imposições ideológicas e culturais das classes dominantes, levadas à cabo durante o processo de implementação do método de alfabetização de adultos, com o intuito de descobrir pistas que possam nos auxiliar a melhor compreender e atravessar a crise político econômico e sociocultural a qual nos encontramos atualmente.

Segundo atesta Faustino Teixeira (1988), o método de alfabetização de adultos de Paulo Freire capacitava seus aplicadores à alfabetizar os alunos num curto espaço de tempo, por volta de 40 horas. Sua estratégia metodológica consistia em,

\begin{abstract}
Partia-se do levantamento do universo vocabular dos educandos, escolhiam-se determinadas palavras desse universo, marcadas de experiência vivida, até se chegar a descobrir as sílabas, as letras e as dificuldades silábicas específicas de seu idioma. Neste processo identificavam-se determinadas 'palavras geradoras' que serviam de material inicial para a descoberta de novas palavras (por exemplo, a palavra geradora ti-jo-lo). As palavras geradoras referendavam uma situação concreta do educando, o que levantava uma discussão em torno da realidade de cada palavra. Estas apontavam questões e temas a serem aprofundados com os animadores (temas geradores). Na medida em que o educando conscientizava-se, através do diálogo crítico, penetrava o universo da alfabetização. $O$ aprendizado das técnicas de ler e escrever associava-se intimamente à tomada de consciência da situação real vivida pelo educando. (TEIXEIRA, 1988, p. 101)
\end{abstract}

O cenário vigente no Brasil, coloca-nos às voltas com problemas semelhantes aos que motivaram Antonio Gramsci (1891-1937) a desenvolver, na Itália, os pressupostos de seu pensamento crítico, voltado ao questionamento da arbitrariedade imposta pela hegemonia ideológica e cultural da burguesia. Segundo Ayala, Ignez e Ayala (1987, p. 47), as obras de Antonio Gramsci começaram a ser publicadas no Brasil em 1966, sendo que sua "importância para a discussão de cultura e cultura popular, vinculada às relações de dominação política, é inegável”.

Assim, o presente artigo visa apresentar brevemente as ideias do sociólogo italiano Antonio Gramsci, responsável por expandir o referencial teórico marxista e por influenciar diretamente no pensamento de Paulo Freire e, por extensão na orientação ideológica, metodológica e prática dos movimentos sociais ligados aos projetos de cultura e educação popular no Brasil.

\footnotetext{
${ }^{2}$ Paulo Freire foi declarado patrono da educação brasileira, tal como atesta-se na Lei n 12.612 de 13/04/2012.
} 


\section{Contextualização do problema}

Há sessenta anos, entre 1960 e 1961, Paulo Freire liderava a sua primeira equipe nordestina ligada ao Serviço de Extensão Universitária da cidade de Recife, responsável por elaborar e aplicar o método de alfabetização de adultos conhecido como "Palavrageradora" junto aos camponeses e proletários.

O projeto inicial previa a implementação de todo um sistema de ensino, que teria início na escola e desembocaria na universidade popular. Assim, o educador, em parceria com jovens intelectuais engajados nos movimentos sociais de esquerda cristã ecumênica, propôs-se a elaborar os termos de uma nova cultura popular, que irrompeu como estratégia política para a inserção das camadas subalternas da sociedade brasileira no cenário político das tomadas de decisão democráticas. Uma vez que, a aquisição da alfabetização se constituía-se como um fator condicionante para o exercício da cidadania através do direito ao voto impresso.

O sucesso da primeira iniciativa de aplicação do método Paulo Freire no município de Angicos, localizado no Rio Grande do Norte e denominado como "Centro Dona Olegarinha", foi reconhecida e o governo de João Goulart financiou a sua ampliação para outros estados da nação. Sendo assim, animadores e agentes de cultura popular ficaram responsáveis por desenvolver e aplicar as metodologias pedagógicas inclusivas e problematizadoras junto aos membros das Comunidades Eclesiais de Base (CEB's) no interior do País. De tal modo, a conquista da cidadania viria pela via do acesso à escola e à educação.

Centenas de alunos se alfabetizaram- e alcançaram o direito ao voto impresso. Contudo, com a deposição de João Goulart da presidência da república, a aplicação do método foi abortada e Paulo Freire, exilado, percorrendo diversos países, onde difundiu o seu método de ensino-aprendizagem. (TEIXEIRA, 1988)

Paulo Freire é aclamado entre intelectuais de universidades por todo o mundo. Sua obra é amplamente discutida e seu método largamente aplicado até os dias de hoje. O reconhecimento do valor de suas contribuições para a educação no exterior é notório. Entretanto, no momento presente, seguidores do Presidente Bolsonaro, influenciados ideologicamente por Olavo de Carvalho, esforçam-se por distorcer os méritos do legado de Paulo Freire para a educação brasileira. Suas ideias têm sido cada vez mais alvo de críticas e ataques nas redes sociais por parte de uma direita fundamentalista e autoritária, caracterizada por rechaçar o papel preponderante que a cultura e a educação desempenham para o pleno exercício da cidadania e para o bom funcionamento da sociedade.

O cenário político nacional tem trazido à tona novamente os tradicionais preconceitos de classe associados às parcelas elitistas da sociedade, que não veem com bons olhos a inserção e participação das camadas populares no cenário democrático. 


\section{-Revista de Iniciação à Docência, v.6 , n. 2, 2021- \\ Publicação: dezembro, 2021 - ISSN 2525-4332}

Nesse sentido, evidencia-se que a emancipação das consciências histórica e política dos povos oprimidos não interessa aos setores dominantes, que buscam a todo custo perpetuar as desigualdades sociais e se manter hegemonicamente no poder.

Nesta gestão do Governo Federal, a educação tem sido a área mais atingida pelos cortes de investimentos públicos. Dentre todos os ministérios, o bloqueio de despesas orçamentárias para a pasta do Ministério da Educação foi o mais incisivo ${ }^{3}$. 0 que denota claramente a postura de perseguição e negação das benesses da educação.

Frente a esse contexto de crise política, cultural e educacional, e levando em consideração as contribuições de Antonio Gramsci e Paulo Freire, parte-se das seguintes questões: Qual o papel dos intelectuais nos processos de organização social? Como a sua atuação pode conferir a emancipação das consciências críticas e histórico- políticas das massas? Como a educação pode contribuir para o rompimento das lógicas de dominação e opressão?

\section{Gramsci e Paulo Freire: confluências teóricas}

Gramsci (1982) refletiu largamente sobre a função dos intelectuais nos processos de elaboração e difusão de uma nova cultura entre as classes subalternas. Segundo sua concepção, pode-se entender como "intelectual orgânico" aquele indivíduo que dispõe seu conhecimento em prol dos movimentos sociais, assumindo uma postura engajada politicamente e cujas atividades produtoras de sentido inserem-se na totalidade das relações sociais. Isto é, o intelectual deve procurar tornar-se parte do povo e promover a socialização do conhecimento entre ele. Partindo dessa premissa, faz-se necessário evidenciar que, para além do fato de um intelectual se dedicar predominantemente às atividades de estudo, pesquisa e produção textual, é imprescindível que a sociedade o reconheça como tal, que admita a indispensabilidade de sua função na divisão social do

\footnotetext{
3 Tal como pode-se verificar através das seguintes matérias reportadas pela mídia no dia 23 de abril de 2021 : Reportagem de Francisco Brandão, editada por Wilson Silveira. Orçamento 2021 é sancionado; Educação, Economia e Defesa têm os maiores cortes. Brasília-DF: Câmara dos deputados. 23 abr. 2021. Política e administração pública. Disponível em: https://www.camara.leg.br/noticias/749955-orcamento-2021-esancionado-educacao-economia-e-defesa-tem-maiores-cortes/. Acesso em: 24 nov. 2021; reportagem de Ana Krüger. Educação concentra maior bloqueio de verbas do orçamento deste ano. Uol, p. Online, 23 abr. 2021. Congresso em Foco: Governo. Disponível em: https://congressoemfoco.uol.com.br/temas/educacao/educacao-concentra-maior-bloqueio-de-verbas-doorcamento-deste-ano/. Acesso em: 24 nov. 2021; reportagem de Cida de Oliveira. Educação é a área mais atingida pelos cortes orçamentários de Bolsonaro: O Ministério da Educação teve R\$ 2,7 bilhões bloqueados e R\$2,2 bilhões vetados pelo presidente. Rede Brasil Atual. São Paulo, p. Online, 23 abr. 2021. Educação. Disponível em: https://www.redebrasilatual.com.br/educacao/2021/04/educacao-e-a-area-maisatingida-pelos-cortes-orcamentarios-de-bolsonarol. Acesso em: 24 nov. 2021 e reportagem de Lorena Rodrigues. Educação é a pasta mais atingida com cortes no orçamento: Pasta perdeu R\$ 2,7 bilhões em recursos, seguida pelo Ministério da Economia, com $\mathrm{R} \$ 1,4$ bilhão; em meio à pandemia Ministério da Saúde foi poupado. Terra, p. Online, 23 abr. 2021. Economia. Disponível em: https://www.terra.com.br/economia/educacao-e-a-pasta-mais-atingida-com-cortes-noorcamento,3934f8f5ccf244819313114d23eob414k864he8k.html . Acesso em: 24 nov. 2021.
} 


\section{-Revista de Iniciação à Docência, v.6 , n. 2, 2021- \\ Publicação: dezembro, 2021 - ISSN 2525-4332}

trabalho. Espera-se que a postura adotada pelo intelectual seja aberta ao diálogo e livre de juízos de valor, num movimento dialético de troca de conhecimentos possibilitada pela esfera da escola. E que a comunidade reconheça a importância de sua atuação para a promoção das transformações socioculturais almejadas, agenciando assim, uma abertura sincera aos processos de aprendizagem por ele propostos.

Na perspectiva gramsciana, o processo educacional reivindica a demanda de uma íntima aproximação entre o "intelectual orgânico" e as classes populares, apontando para a elaboração de uma 'Filosofia da Práxis', onde os postulados teóricos e a ação prática encontram-se amalgamados.

Desse modo, para Gramsci (1982), a educação e a cultura instauram-se num campo de interação social no qual teoria e prática devem unir-se e confundir-se, de sorte que os processos educacionais envolvam, igualmente, a dimensão da ação social e a da ação política.

O autor se empenhou essencialmente em evidenciar a relevância do papel da cultura, da educação e dos intelectuais nos processos de transformação social. Em suas formulações a cultura é entendida como,

[...] organização, disciplina do próprio eu interior, é tomada de posse da própria personalidade, é conquista de consciência superior pela qual se consegue compreender o próprio valor histórico, a própria função da vida, os próprios direitos e os próprios deveres. (GRAMSCl, 1976, p. 83)

Com sua análise sobre a noção de hegemonia, defende que exista, acentuadamente, um importante e indubitável nexo travado entre a política e educação manifesto na dimensão cultural. E nesse sentido, postula que a dominação do capitalismo não se realizava pura e simplesmente por intermédio da coerção de forças físicas e jurídicas, mas sim, igualmente e sutilmente, através da hegemonia das ideias. O que implica que a ideologia da classe dominante se vulgariza no senso comum a partir do cidadão médio por meio da linguagem, da moral, da educação e, especialmente, da cultura. Dessarte, tem-se que a hegemonia ideológica burguesa atua moldando as convicções e aspirações da classe trabalhadora, que em contrapartida, precisa se atentar para esse fato e promover rupturas com esse padrão injustamente arraigado. O autor constata que, embora a noção corrente de ideologia tenha aparecido mais amplamente associada à sua relação com a política, vale destacar que, ela encontra notório terreno de reprodução nos corriqueiros âmbitos da linguagem e da cultura.

Para Gramsci, o "intelectual orgânico" articula três aspectos fundamentais à sua práxis: a noção de que a socialização do conhecimento parte de sua expertise e iniciativa de partilha, considera a divisão socialmente admitida entre "cultura popular" e "cultura erudita" e postula que tanto o "trabalho concreto" quanto o "trabalho abstrato" propiciam a produção de uma filosofia espontânea.

Partindo desse viés de raciocínio, podemos fazer um paralelo entre as reflexões do autor sobre o papel do "intelectual orgânico" com o de "educador popular", admitido 


\title{
-Revista de Iniciação à Docência, v.6 , n. 2, 2021- \\ Publicação: dezembro, 2021 - ISSN 2525-4332
}

pelos pressupostos ideológicos do pensamento de Paulo Freire. De forma que, quando Freire defende a importância que o "educador popular" exerce para uma determinada comunidade, ele vai ao encontro com as ideias de Gramsci sobre o papel preponderante que o "intelectual orgânico" desempenha na sociedade. No qual o educador, a partir de seu posicionamento em relação aos alunos, compromete-se com a difusão horizontal do conhecimento, em detrimento de impor hierarquias e distanciamentos. Pois, tal como reitera Peter Mayo com relação ao entendimento de Paulo Freire sobre a função do intelectual: "[...] a sua concepção está mais na linha de análise de Gramsci sobre o papel que ele ou ela realiza tanto em apoiar/cimentar os arranjos hegemônicos existentes ou em desafiá-los." (MAYO, 2018, p. 272).

Na concepção do educador brasileiro, o "intelectual orgânico" atuando como "educador popular" a que ele reconhece é aquele indivíduo que por intermédio da aplicação de um método transformador e contestador do status quo pautado por um diálogo conduzido pelo debate de temas políticos, elabora juntamente com seus educandos uma nova consciência crítica, comprometida com a implementação de transformações que se orientam "de dentro pra fora" e "de baixo pra cima" e cujos reflexos são experimentados no dia a dia dessas comunidades. Trata-se de uma educação contra a alienação e a favor da libertação.

Dessa forma temos que,

\begin{abstract}
O educador crítico, no sentido de Freire, é um intelectual crítico que, dados seu preparo e sua competência, tem uma autoridade que é aceita pelos participantes do contexto educacional, mas que é suficientemente humilde e democrático para que essa autoridade não se degenere em autoritarismo. 0 educador crítico toma posição e dirige o processo de aprendizagem, despertando curiosidade epistemológica, mas deve estar aberto para reaprender de seus educandos, que oferecem diferentes perspectivas, muitas delas derivadas de sua respectiva localização social, que incidem sobre o objeto da coinvestigação. (MAYO, 2018, p. 273)
\end{abstract}

Sendo assim, se Gramsci (1982) questionou a arbitrária apropriação ideológica da cultura e da educação por parte da burguesia ao criticar a distinção correntemente feita pelos pensadores da época entre o "trabalho manual" - concreto e o "trabalho intelectual" - abstrato, defendendo que ambos os tipos de labores são produtores de uma filosofia espontânea que lhes é concernente e que, portanto, essa distinção assume caráter terminantemente ideológico. Paulo Freire (2019) entra em cena no Brasil fazendo afirmações similares, porém, adaptadas ao contexto nacional, em que se percebe a replicação dessa tendência à valorização das produções culturais espontâneas do povo, ao invés das costumeiras reproduções mecanizadas e irrefletidas da cultura hegemônica. Ao partir em defesa de uma educação popular pautada pela valorização das expressões culturais e semânticas elaboradas pelos sujeitos integrantes das camadas subalternas, Freire coaduna largamente com o pensamento do sociólogo italiano.

É nesse sentido que Peter Mayo afirma, 


\section{-Revista de Iniciação à Docência, v.6 , n. 2, 2021- Publicação: dezembro, 2021 - ISSN 2525-4332}

Antônio Gramsci via na educação e na formação cultural de adultos a chave para a criação da ação contra hegemônica. Ele considerava essenciais esses processos para que os grupos sociais subordinados se engajassem com sucesso na "guerra de posição" necessária para desafiar o Estado burguês e transformá-lo em um Estado que representasse interesses mais amplos. [...] O desafio é, a partir dos insights de Gramsci, desenvolver uma estratégia de educação de adultos que contribuirá para transformar a sociedade em uma outra que represente os interesses de todos aqueles grupos de pessoas que, sob as atuais circunstâncias ocupam uma posição subordinada na estrutura de poder. (MAYO, 2004, p. 53)

As reflexões gramscianas assinalam que cada grupo social possuí sua própria estratificação intelectual e que em determinados momentos históricos certos grupos específicos sobressaem-se e subjugam outros. Para o autor, conforme destaca Monasta, "A função dos intelectuais "orgânicos" é a de liderar "intelectual e moralmente" a sociedade, por meio da educação e da organização da cultura, e não por meio dos tradicionais métodos de coação jurídica e policial." (MONASTA, 2010, p. 23-24)

Com efeito, essa perspectiva compreende que todo homem e toda mulher estão inevitavelmente associados à condição de intelectual. Pois, Gramsci se empenhou amplamente em desconstruir a ideia de que a filosofia era produzida apenas por eruditos e que ficava, portanto, restrita a eles. Ele buscou desmistificar o papel intelectual exercido pelo sujeito simples, apontando para sua capacidade de se expressar autônoma e filosoficamente. Por esse ângulo, admite-se que todos os homens fazem filosofia, que são todos filósofos natos, pensadores de uma filosofia espontânea, habilitada a expressar-se a partir das próprias categorias de significação semântica e cognoscente, partindo de suas próprias cosmovisões e entendimentos sobre da realidade. Trata-se do fomento de uma filosofia originada no senso comum e que se vale substancialmente da cultura popular para sua criação e difusão.

A noção gramsciana de intelectual provém da análise das contradições, limites e repercussões da hegemonia ideológica para a configuração do pensamento do senso comum. E é justamente por essa razão que o autor pode servir como parâmetro epistemológico para a compreensão da função exercida pelos intelectuais na realidade brasileira, pois suas colaborações atuaram como inspirações à ação sociopolítica e educativo-cultural dos educadores populares.

As contribuições de Gramsci para o pensamento de Paulo Freire e, por extensão, para o pensamento dos intelectuais engajados nos movimentos sociais ligados aos preceitos da Teologia da Libertação, trazem precipuamente a concepção do papel desempenhado pelo "intelectual orgânico" frente ao novo processo cultural que se afirmava, aliando um movimento de organização prática e política ao desenvolvimento da abordagem teórica. De forma que, eles procediam a uma redescoberta do papel da cultura popular, passando a admitir que a cultura não se restringia especificamente ao domínio dos intelectuais acadêmicos, num movimento que passava a valorizar as manifestações espontâneas do povo oprimido. 


\section{-Revista de Iniciação à Docência, v.6 , n. 2, 2021- \\ Publicação: dezembro, 2021 - ISSN 2525-4332}

Seus esforços baseiam-se na necessidade de se pensar a figura do educador, ou seja, o papel do "intelectual orgânico", como competência privilegiada de concretização de uma educação voltada à emancipação do ser humano, priorizando uma educação que se estabelece numa via de mão dupla entre o professor e o aluno.

Gramsci na Itália, antes mesmo de Paulo Freire no Brasil, já defendia a necessidade da participação popular nos processos históricos de construção do pensamento, bem como, já valorizava as criações artísticas e culturais populares. Ao afirmar que todos os sujeitos são intelectuais, na medida em que elaboram, interpretam e compartilham de uma filosofia espontânea, construída por eles a partir de suas próprias categorias de significação cultural, o autor promove visibilidade a setores sociais marginalizados e considerados destituídos de uma cultura passível de ser reconhecida e analisada a partir de sua própria voz.

\section{Intelectuais engajados e os movimentos sociais de cultura e educação popular}

Pode-se afirmar que a crise política originada pelo Golpe Civil Militar, na segunda metade da década de 1960, foi um dos fatores que motivaram o educador Paulo Freire a desenvolver um método de alfabetização de adultos, associado à um projeto de conscientização política e histórica, comprometida com a inserção das camadas desprivilegiadas da sociedade brasileira no cenário democrático eleitoral. Para cumprir esse desafio, o professor contou com a colaboração de jovens intelectuais vinculados aos movimentos sociais. Pois, tal como defende:

\section{Não existe conscientização se a prática não nos leva a acção consciente dos oprimidos como classe social explorada na luta pela sua libertação. Por outro lado, ninguém conscientiza ninguém. $O$ educador e o povo consciencializam-se através do movimento dialético [...]. (FREIRE, 1978, p. 17)}

Fruto da ação recíproca entre educador e educando, a educação popular constituía-se como uma esfera de formação ampla do sujeito sociocultural, denotando um processo de humanização e conscientização, aprimorando as dimensões de entendimento histórico-político e as habilidades laborais de cada sujeito envolvido nas dinâmicas de ensino-aprendizagem. O acesso ao conhecimento, a conquista da alfabetização e por decorrência da cidadania, as relações sociais travadas no interior desses núcleos de promoção da educação popular e as experiências artístico culturais contribuíam para a emancipação do pensamento e o melhoramento da vida social desses camponeses e proletários assistidos.

As ideias de Paulo Freire influenciaram o pensamento de intelectuais pertencentes a diversos movimentos sociais brasileiros e latino-americanos vinculados à esquerda militante, que compartilhavam dos mesmos pressupostos cristãos e ecumênicos da Teologia da Libertação, tais como: a Juventude Universitária Católica (JUC), o Movimento de Educação de Base4 (MEB), a Ação Popular (AP), o Centro Ecumênico de

\footnotetext{
${ }^{4}$ O MEB foi criado em 1961 pela Conferência Nacional dos Bispos do Brasil (CNBB) em parceria com o
} 


\section{-Revista de Iniciação à Docência, v.6 , n. 2, 2021- \\ Publicação: dezembro, 2021 - ISSN 2525-4332}

Documentação e Informação (CEDI) e a Igreja e Sociedade na América Latina (ISAL).

Tratava-se de uma juventude imbuída da responsabilidade da denúncia acerca das desigualdades sociais e envolvida na luta por transformações culturais, econômicas e sociopolíticas, que vislumbravam que o problema da falta de educação do povo brasileiro se dava em decorrência das arbitrariedades do Imperialismo excludente. E em contrapartida, acreditavam que somente a superação desses entraves através dos processos de educação e cultura popular conduziriam à libertação.

Partindo dessa perspectiva, podemos asseverar que as práticas profissionais desenvolvidas pelos intelectuais engajados brasileiros, igualmente, encontravam correspondência de princípios ideológicos no que seria considerado o "intelectual orgânico" para Gramsci.

A preocupação com as causas dos povos oprimidos e com a implementação de um projeto de educação e valorização da cultura popular, aglutinavam o interesse desses jovens intelectuais militantes em torno de uma práxis emancipatória e engajada politicamente.

A partir de 1963, as ideias de Paulo Freire passaram a ganhar maior visibilidade e experimentam uma progressiva integração junto ao corpo teórico do MEB, que passou a aplicar o seu método pedagógico de alfabetização de adultos "Palavra-Geradora" nas CEB's. Em setembro desse ano aconteceu no Recife, o "I Seminário de Alfabetização e Cultura Popular", promovido pelo Ministério de Educação e Cultura, em que participaram 76 organizações que trabalhavam com alfabetização de adultos e cultura popular. Conforme atesta Brandão, "o pessoal do MEB pega o método Paulo Freire e transforma num sistema Paulo Freire mais indutivo" (BRANDÃO [entrevista concedida a] FERNANDES; ALVARENGA; SPIGOLON, 2017, p. 8).

A atuação dos integrantes do MEB nos processos de implementação do método de alfabetização de adultos elaborado por Paulo Freire junto às CEB's espalhadas pelo interior do país, especialmente, nas regiões Norte, Nordeste e Centro Oeste, foi de extrema importância. Pois, se foi Paulo Freire quem o elaborou, foram os agentes de cultura e de educação popular, entre animadores e coordenadores, quem o difundiram e o colocaram em prática. Foram eles que lidaram com os erros e os acertos das vias de fato da execução desse projeto.

Ao se disporem a aplicar e a vivenciar o método da "Palavra- Geradora" no dia a dia da vida dessas comunidades carentes, esses educadores inspiraram o próprio Paulo Freire para a produção de seu célebre livro, “Pedagogia do Oprimido" (2019). Haja visto que, o livro é originado, exatamente, dessas primeiras experiências educacionais desenvolvidas pelos agentes do MEB nas CEB's.

governo federal. 


\section{-Revista de Iniciação à Docência, v.6 , n. 2, 2021- Publicação: dezembro, 2021 - ISSN 2525-4332}

A proposta dos educadores populares previa uma inversão cultural da sobressalência da orientação erudita e dominante sobre a cultura popular, num projeto que almejava a ruptura social das desigualdades e das injustiças acometidas à pessoas e comunidades populares. Neste momento os intelectuais engajados com a cultura popular dos anos 1960 propõem alternativas práticas para o enfrentamento desse quadro excludente. Nesse sentido, a ruptura inovadora que provocam busca repensar o processo cultural e o exercício da educação desde o seu interior, atuando como uma contribuição revolucionária na questão da participação de intelectuais militantes e comprometidos com as causas populares, no bojo de um projeto de libertação. (BRANDÃO; FAGUNDES, 2016)

A ideia de uma educação desvinculada dos padrões mecanicistas e seculares convencionais, reconhecidos por conceber o processo de aprendizagem nos termos de uma irrefletida reprodução memorizada de sentenças vazias e descontextualizadas da vida real dos sujeitos, passou a ser veementemente criticada e como alternativa viável, delineava-se a proposta de uma educação inclusiva e pautada pelas próprias categorias de significação sociocultural dos educandos. Tratava-se de uma educação contestatória e libertária, com vistas a suscitar mudanças estruturais imprescindíveis na sociedade brasileira.

Esses estudantes engajados na efetivação de uma práxis educativa transformadora, adotaram o método de alfabetização de adultos proposto por Paulo Freire, que propunha o envolvimento e a atuação participativa dos educandos. Suas dinâmicas organizavam-se da seguinte maneira: primeiramente, os animadores promoviam atividades de roda, conhecidos como "círculos de cultura", nos quais os alunos podiam se apresentar e juntos levantar temas pertinentes de serem trabalhados. Desse jeito, refletiam sobre questões que envolvessem a realidade de suas próprias comunidades, ao passo que se colocavam no desafio de aprender a ler e a escrever. Os "círculos de cultura" igualmente foram agenciados por Gramsci no contexto italiano das indústrias e do proletariado, onde os operários se reuniam em Conselhos de Fábrica para elaborar os preceitos de uma reforma intelectual e cultural.

O método elaborado por Paulo Freire propunha que os educandos descobrissem letras e palavras conexas às suas dinâmicas de vida, de modo que tal processo conduziria à alfabetização. Aprendia-se, assim, a ler as letras, as palavras e o mundo.

O método em questão, partia do princípio pedagógico de que transformações sociais profundas e irreversíveis na sociedade deveriam advir de mudanças pessoais e interativas nas consciências de pessoas e de grupos provenientes das classes

\footnotetext{
5 Segundo o educador popular Carlos Rodrigues Brandão: “[...] o círculo de cultura dispõe as pessoas ao redor de uma "roda de pessoas", em que visivelmente ninguém ocupa um lugar proeminente. O professor que sabe e ensina quem não sabe e aprende, aparece como o monitor, o coordenador de um diálogo entre pessoas a quem se propõe construírem juntas o saber solidário a partir do qual, cada um ensina- eaprende." (Brandão apud STRECK; REDIN, ZITKOSKI, 2018a, p. 81)
} 


\section{-Revista de Iniciação à Docência, v.6 , n. 2, 2021- \\ Publicação: dezembro, 2021 - ISSN 2525-4332}

trabalhadoras, cujas implicações abrangeriam o escopo de uma múltipla releitura popular de suas próprias e diversificadas tradições culturais. Dessa forma, as novas ações educativas e políticas esboçadas pelos educadores populares conjuntamente com os alunos através das várias situações pedagógicas de diálogos e de trocas efetivadas na escola, deveriam ser revisitadas e revistas mediante a resolução de leituras críticas, que levassem em consideração o dimensionamento da realidade social à qual seus educandos estariam envolvidos, bem como a elaborar em parceria com eles, os caminhos para a superação das limitações sociais identificadas (BRANDÃO, 2017).

O corpo de intelectuais ligados aos movimentos sociais responsáveis pela implementação do método Paulo Freire era composto por cristãos militantes de orientação ecumênica, entre leigos e sacerdotes. Eles estiveram associados desde os primórdios aos movimentos de cultura popular, a começar pelo MEB. Foram eles que criaram ainda no começo dos anos 1970 a AP, considerada uma extensão da JUC. Concomitantemente, ao longo de toda a América Latina surgiram outras frentes ecumênicas comprometidas com os processos educacionais e com a difusão do conhecimento e a conscientização política, tais como a ISAL (Igreja e Sociedade na América Latina), o CEAAL (Conselho Latino-Americano de 'Educação de Adultos' -depois, de "Educação Popular") e o CREFAL (Centro Regional de Educación de Adultos de América Latina) e o CEDI (Centro Ecumênico de Documentação e Informação) no Brasil (BRANDÃO, 2018c, 2019).

A Teologia da Libertação surge em decorrência desse contexto de articulações ideológicas libertárias, configurando-se a partir de múltiplas influências, que iam desde uma cosmovisão cristã, cujo personalismo e humanismo compunham a tônica ideológica, ao marxismo e o gramscianismo. Seus agentes partiam de concepções teológicas renovadas, porém, baseadas na amplificação da perspectiva de Marx e de seus seguidores, tais como Gramsci e o próprio Paulo Freire (CAMPOS, 2014).

O pensamento de Paulo Freire, cuja produção teórico-prática resultou na publicação do livro “Pedagogia do Oprimido" (2019), foi largamente inspirado pela atuação dos educadores populares que atuaram junto ao MEB. E nesse sentido, pode-se afirmar que a pedagogia freiriana e a Teologia da Libertação influenciaram-se mutuamente. Pois, foram os integrantes do MEB, vinculados à setores da Igreja Católica que se lançaram no desafio de promover práticas educacionais junto a camponeses e proletários do interior do Brasil através das CEB's, sendo, portanto, os responsáveis por implementar os métodos pedagógicos de alfabetização de adultos elaborados pelo educador.

De acordo com a lógica que inspirou a produção do livro, "Pedagogia do Oprimido", tal processo de emancipação das consciências deveria se iniciar com o procedimento dos métodos da alfabetização de adultos que, inovadoramente, se pautavam por uma técnica rápida e eficaz, que pode atribuir o seu sucesso, justamente, 


\section{-Revista de Iniciação à Docência, v.6 , n. 2, 2021- \\ Publicação: dezembro, 2021 - ISSN 2525-4332}

ao fato de ter conseguido alcançar o entendimento daquela gente simples, configurandose como um método acessível à linguagem deles, uma vez que, se valia, acima de tudo, do universo vocabular e das próprias categorias de significação sociocultural administradas pelos educandos, envolvidos participativamente em suas estratégias de alfabetização e conscientização emancipatória.

As CEB's funcionavam como escolas alternativas, concentrando tanto práticas educacionais como pastorais, acolhendo reuniões da comunidade e servindo como espaço aberto para as dinâmicas de ensino-aprendizagem (TEIXEIRA, 1988).

O encontro entre a pedagogia freiriana e a Teologia da Libertação no interior das CEB's foram cruciais para o sucesso do projeto de alfabetização de adultos, que aliava a base da população brasileira, os pobres, com os pressupostos de uma educação inclusiva e de teologia cristã ecumênica direcionada à efetivação de uma práxis transformadora baseada no evangelho de Jesus Cristo (DIAS, 2007).

Em seu livro "Os cristãos e a libertação dos oprimidos" (1978), Freire chama a atenção para o caráter revolucionário da Teologia da Libertação e reconhece a importância que os teólogos e os intelectuais cristãos de esquerda e de orientação ecumênica desempenharam para a implementação das tão necessárias transformações sociais que se impunham naquele contexto.

Carlos Rodrigues Brandão era um desses educadores populares vinculados à esquerda cristã ecumênica, engajado nos processos de implementação do método Paulo Freire nas CEB's. Logo no início do projeto, o intelectual foi designado para um treinamento do MEB na região Nordeste, para atuar na cidade de Garanhuns, palco de iniciativas pioneiras de educação popular, localizada no agreste pernambucano, integrando-se à “Equipe de Animação Popular”. E, posteriormente, participou de intensas jornadas de estudos e debates ao redor do tema da educação popular, tanto no Brasil, quanto em outros países da América Latina, durante o período de duração da ditadura civil-militar. (BRANDÃO, 2017)

De acordo com a concepção do professor Brandão (2018b), Paulo Freire pensava a educação como cultura, encarava a cultura como história e entendia a história como sendo o resultado da criação humana, na qual a partir da aplicação do método extraído de uma práxis educacional comprometida com as causas sociais dos oprimidos, essa história poderia ser reorientada, assumindo, desse modo, uma direção essencialmente humanitária.

Conforme coloca Brandão (2006), essa preocupação com a questão da educação, inclusive, influenciou de forma indireta a formação do Partido dos Trabalhadores (PT) e do Movimento dos Trabalhadores Rurais Sem Terra (MST), que encontraram na educação popular desenvolvida nas CEB's e pautadas pela Teologia da Libertação, os alicerces para a sua atuação política. 


\section{-Revista de Iniciação à Docência, v.6 , n. 2, 2021- \\ Publicação: dezembro, 2021 - ISSN 2525-4332}

À despeito das acusações difamatórias da direita de que Paulo Freire promovia uma doutrinação marxista, Brandão (2018c) ressalta que, o livro "Pedagogia do Oprimido" (2019) não se configurava necessariamente como uma obra de caráter declaradamente marxista, pois em momento algum do texto houve menção explícita à Marx. No entanto, existe a referência direta a outros autores que, igualmente, beberam em suas fontes teórico-revolucionárias, tais como Gramsci, Fidel Castro e Mao Tsé Tung.

Contudo, em $1^{\circ}$ de abril de 1964, foi deflagrado um Golpe de Estado que mudou os rumos da história brasileira e incidiu na asfixia das liberdades democráticas. A "Campanha Nacional de Alfabetização" foi abortada, muitos dos integrantes do MEB foram perseguidos, presos, torturados, exilados e/ou mortos. Paulo Freire foi exilado, transferindo-se, inicialmente, para o Chile e depois para os Estados Unidos, onde chegou a lecionar na Universidade de Harvard (RAMOS, 2014).

O método freiriano conduzia a uma forma de aprendizagem rápida e extremamente eficaz, caracterizada por levar em consideração a liberdade do aluno. $\mathrm{O}$ educador defendia a adoção de um método educacional pautado pelo respeito à dignidade dos camponeses e proletários, capaz de valorizar a sua cultura e atuar junto a eles no sentido da construção do seu conhecimento, e por suposto, repelia qualquer proposta massificadora ou arbitrariamente diretiva. Conforme ratifica Saviani (2008),

Pretendia-se desenvolver uma educação genuinamente brasileira visando à conscientização das massas por meio da alfabetização centrada na própria cultura do povo. A prática que se buscou implementar visava aproximar a intelectualidade da população, travando um diálogo em que a disposição do intelectual era a de aprender com o povo, despindo-se de todo o espírito assistencialista. (SAVIANI, 2008, p. 318)

Todo o processo da educação popular não era instrumental, mas sim, crítico e participativo, regido por uma horizontalidade com relação à troca dos saberes. Ainda que se reconhecesse o papel relevante do intelectual para conduzir essas dinâmicas educacionais. Acreditava-se que somente um povo consciente acerca dos processos de exclusão aos quais está submetido e contestador de sua situação de exploração poderia fazer frente às agruras da manipulação ideológica das classes dominantes. É nesse sentido que a educação aparece como o principal instrumento para a promoção dessas transformações nas mentalidades.

O conhecimento é adquirido na partilha, de maneira ativa e afetiva. É um saber que se aprende na troca entre educador e educando e aponta para a superação da condição de dependência e subjugação.

A função do "intelectual orgânico" gramsciano atuando como "educador popular" freiriano assenta-se na iniciativa de despertar a consciência crítica dos educandos que, assim, podem melhor avaliar a sua participação no cenário democrático. Do mesmo modo, pode-se afirmar que as categorias: cultura, educação, ideologia e religião se cruzaram no horizonte de uma práxis política engajada, levada à cabo pelos 


\section{-Revista de Iniciação à Docência, v.6 , n. 2, 2021- \\ Publicação: dezembro, 2021 - ISSN 2525-4332}

intelectuais brasileiros enredados nas lutas por transformações sociais, visando o reconhecimento e a valorização da cultura dos integrantes das classes populares.

\section{Considerações finais}

Defende-se que o "intelectual orgânico" de Gramsci assume no contexto brasileiro a alcunha de "educador popular". Pois foi, justamente, essa concepção dialógica, integrativa, participativa e horizontal posta em prática pelos educadores populares desde as primeiras experiências de aplicação do método da "Palavra-Geradora", que a ideia de uma pedagogia transformadora e inovadora, centrada na autonomia, na igualdade, na criticidade, na criatividade, na solidariedade e na liberdade da participação de sujeitos conscientes, em relações interativas travadas em seus respectivos cenários de vida, trabalho e aprendizagem, pode se desenvolver.

A educação era encarada tanto por Gramsci, quanto por Paulo Freire como uma ferramenta essencial para conscientização e emancipação de camadas populares da sociedade, que através de uma experiência comunitária e o aperfeiçoamento de sua consciência crítica e histórica, tornam-se capazes de promoverem transformações sociais cruciais em seus modos de vida.

No contexto brasileiro, o educando ao passo que se alfabetizava, adquiria o direito de votar nas eleições usando as cédulas de papel. E com isso, eles tinham garantida e viabilizada a sua inserção no cenário democrático, podiam escolher seus candidatos e participar das tomadas de decisão políticas. O que acarretou mudanças substanciais na organização social nacional.

Tanto o sociólogo italiano, quanto o educador brasileiro defendem a relevância da participação das camadas populares da sociedade nos processos políticos de tomadas de decisão, que emergem de seus contextos de exclusão, deixando de serem simples objetos de ações assistencialistas para tornarem-se atores participativos dos processos político democrático, econômico e socioculturais.

As confluências entre o pensamento de Freire e Gramsci se relacionam na medida em que apontam para o caráter potencialmente libertador da educação. Ambos os autores defendiam que o papel da educação e da cultura era preponderante para a emancipação das consciências das agruras do capitalismo excludente.

Uma prática educacional libertadora deveria envolver um trabalho intelectual organicamente construído junto à comunidade, para que assim, haja uma reelaboração dos elementos ideológicos da cultura do povo. Trata-se de uma ação cultural vocacionada à reconstrução das estratégias e dos sentidos de propagação do conhecimento.

Depois de décadas o pensamento de Paulo Freire continua a incomodar as elites, que testemunharam os filhos das empregadas domésticas compartilhando dos mesmos bancos universitários que os filhos dos patrões. Suas ideias voltaram a ser combatidas. 


\section{-Revista de Iniciação à Docência, v.6 , n. 2, 2021- \\ Publicação: dezembro, 2021 - ISSN 2525-4332}

Definitivamente estamos vivenciando tempos de ataque à educação, ao livre pensar, às instituições educacionais, como a escola e a universidade. Ao passo que, a desinformação tem causado prejuízos incalculáveis como a propagação das fake News e a ascensão de conservadorismos, que trazem à tona conflitos envolvendo crenças religiosas e preconceitos morais, resultantes de uma radicalização castradora das liberdades. O que nos leva a questionar se existe autonomia nas relações educacionais que se produzem no contexto atual.

Inspirados nesses mestres podemos deferir que a chave para o enfrentamento dessa situação de crise continua centrada na potencialidade libertadora da educação e que o papel dos professores frente a este contexto é crucial e indispensável. A educação deveria conduzir um diálogo crítico e reflexivo. O educador para a liberdade deve trazer à sua prática a essência do "intelectual orgânico" e do "educador popular".

\section{Referências}

AYALA, Marcos; IGNEZ, Maria e AYALA, Novais. Cultura popular no Brasil: perspectivas de análise. São Paulo: Ática, 1987. (Série Princípios)

BRANDÃO, Carlos Rodrigues. A pesquisa participante e a participação na pesquisa: um olhar entre tempos e espaços a partir da América Latina. In: BRANDÃO, Carlos Rodrigues; STRECK, Danilo Romeu (org.). Pesquisa participante: a partilha do saber. Aparecida: Ideias Letras, p. 17-54, 2006.

BRANDÃO, Carlos Rodrigues. A educação como cultura. Memória dos anos sessenta. Horizontes Antropológicos. Porto Alegre, ano 23, n. 49, set./dez, p. 377-407, 2017.

Disponível em:

https://www.scielo.br/j/ha/a/JXKXLMzzHtJCsDBJ74gqndF/?lang=pt\&format=pdf. Acesso 15 set. 2021.

BRANDÃO, Carlos Rodrigues. Círculo de Cultura. In: STRECK, Danilo R.; REDIN, Euclides; ZITKOSKI, Jaime José (org.). Dicionário Paulo Freire. 4.ed. Belo Horizonte: Autêntica, p. 80-82, 2018 .

BRANDÃO, Carlos Rodrigues. Método Paulo Freire. In: STRECK, Danilo R.; REDIN, Euclides; ZITKOSKI, Jaime José (org.). Dicionário Paulo Freire. 4.ed. Belo Horizonte: Autêntica, p. 313-314, 2018b.

BRANDÃO, Carlos Rodrigues. A pessoa de Paulo- Memórias, depoimentos. Campinas-SP: Livro Livre/UFES, 2018c. Disponível em:

https://educacaodocampo.ufes.br/sites/educacaodocampo.ufes.br/files/field/anexo/a_pes soa_de_paulo.pdf. Acesso em: 14 jun. 2021.

BRANDÃO, Carlos Rodrigues. A Educação Popular e o CEAAL na linha do tempo: memórias e reflexões de um educador dos anos sessenta. Campinas-SP: Livro Livre/ Revista Piragua, 2019. Disponível em: https://apartilhadavida.com.br/wpcontent/uploads/escritos/EDUCA $\%$ C $3 \% 87 \%$ C $3 \% 83$ /PESSOA $\% 20$ E $\% 20$ EDUCA $\%$ C $3 \% 87 \%$ C $3 \% 830$ |A\%20EDUCA\%C3\%87\%C3\%83O\%20POPULAR\%20\%20NA\%20LINHA\%20DO\%20TEMPO\%20\%20rosa\%20dos\%2oventos.pdf. Acesso em: 24 nov. 2021.

BRANDÃO, Carlos Rodrigues; FAGUNDES, Maurício Cesar Vitoria. Cultura popular e 
educação popular: expressões da proposta freireana para um sistema de educação. Curitiba, Educar em Revista. $n^{\circ}$ 61, Jul/set, p. 89-106, 2016. Disponível em: https://www.scielo.br/j/er/a/KmYHVqgFMPBfJTjXsRjFFvc. Acesso em: 24 nov. 2021.

CAMPOS, Leonildo Silveira. Os evangélicos, o Golpe e a Ditadura: o irreversível canto das sereias autoritárias. In: DIAS, Zwinglio Mota. Memórias ecumênicas protestantes- os protestantes e a ditadura: colaboração e resistência. Zwinglio Mota Dias (org.) Rio de Janeiro: KOINONIA Presença Ecumênica e Serviço, p. 177-1912014. Disponível em: https://kn.org.br/protestantes/downloads/PDF_Memorias\%20Protestantes.pdf. Acesso em: 23 nov. 2021.

DIAS, Agemir de Carvalho. O movimento ecumênico no Brasil (1954-1994). A serviço da Igreja e dos Movimentos Populares. Tese de Doutorado em História. Universidade Federal do Paraná, Curitiba, 2007. Disponível em:

https://acervodigital.ufpr.br/bitstream/handle/1884/14054/Tese_doutorado_Agemir _ M ovimento\%20ecum\%C3\%AAnico.pdf?sequence=1\&isAllowed=y. Ácesso em: 23 nov. 2021.

FERNANDES, André Paixão; ALVARENGA, Marcia; SPIGOLON, Nima. Entre árvores e sabiás, memórias de Paulo Freire- conversa com Carlos Rodrigues Brandão. E-Mosaicos. Revista Multidisciplinar de Ensino, Pesquisa, Extensão e Cultura do Instituo de Aplicação Fernando da Silveira (CAp-UERJ) v. 6- $\mathrm{n}^{\circ}$ 13, dez. 2017. Disponível em: https://www.epublicacoes.uerj.br/index.php/e-mosaicos/article/view/31897/22842. Acesso em: 12 jul. 2021.

FREIRE, Paulo. Os cristãos e a libertação dos oprimidos. Lisboa: Edições Base, 1978. FREIRE, Paulo. Pedagogia do oprimido. 71 ed. Rio de Janeiro/São Paulo: Paz e Terra, 2019. GRAMSCl, Antonio. Os intelectuais e a organização da cultura. 4.ed. Rio de Janeiro: Civilização Brasileira, 1982.

GRAMSCI, Antonio. Escritos políticos. Lisboa: Seara Nova, 1976.

MAYO, Peter. Intelectual/Intelectuais. In: STRECK, Danilo R.; REDIN, Euclides; ZITKOSKI, Jaime José (org.). Dicionário Paulo Freire. 4.ed. Belo Horizonte: Autêntica, p. 271-273, 2018.

MAYO, Peter. Gramsci, Freire e a educação de adultos: possibilidades para uma ação transformadora. Porto Alegre: Artmed, 2004.

SAVIANI, Demerval. História das ideias pedagógicas. Campinas: Autores Associados, 2008.

TEIXEIRA, Faustino. A gênese das CEB'S no Brasil: elementos explicativos. São Paulo: Paulinas, 1988.

RAMOS, Jovelino. Perseguições, Denúncias, Sofrimentos e Resistência- Depoimentos e Entrevistas. In: DIAS, Zwinglio Mota (org.). Memórias ecumênicas protestantes- os protestantes e a ditadura: colaboração e resistência. Rio de Janeiro: Koinonia: Presença Ecumênica e Serviço, p. 25-35, 2014. Disponível em:

https://kn.org.br/protestantes/downloads/PDF_Memorias\%20Protestantes.pdf. Acesso em: 03 jul. 2021.

Recebido: 24.08.2021

Aprovado: 29.11.2021 